\title{
Degenerative Progressive Myoclonic Epilepsy Electrokymographic Observations
}

\author{
Iraj Derakhshan, Jamshid Lotfi and Kazem Abbsssioun.
}

\begin{abstract}
SUMMARY: Clinical and pathological findings in two cases of degenerative progressive m!oclonic epileps!' (PME) are described. The clinically difficult task of differentiating a "cerebellar" tremor from an action myoclonus is emphasized. Simultaneous electroencephalography and electrokymography w'as done, using capacity to ground transients for recording hand movements. This method was found useful in corroborating the cerebellar nature of the remaining disorder, after successful treatment of the myoclonic element with anticonvulsants.
\end{abstract}

RÉSUMÉ: Nous décrivons les observations cliniques et pathologiques chez deux cas d'épilepsie myoclonique dégénérative progressive (PME). La difficulté dans la différenciation clinique du tremblement "cérébelleux" et du myoclonus d'action est soulignée. Une électroencéphalographie fut faite simultanément à une électrokymographie en utilisant une nouvelle méthode d'enregistrement des mouvements des mains. Cette méthode s'avéra utile pour étudier la nature cérébelleuse du désordre restant après le traitement efficace de l'élément myoclonique par les anticonvulsivants.

From the Departments of Neurology and Neurosurgery, Dariush-Kabir Medical School, Tehran University, Tehran, Iran.

Reprint requests to: Iraj Derakhshan, 1670 Sheridan Road, South Euclid, Ohio 44121 U.S.A.
Progressive myoclonic epilepsy (PME) is a syndrome having different genetic, clinical and pathological varieties (Halliday, 1967). Nosological controversy exists between the degenerative type of this condition and Ramsay-Hunt's dyssynergia cerebellaris myoclonica (DCM) (Radermecker, 1977). This confusion is, in part, caused by problems of phenomenological interpretations regarding the existence of distinct cerebellar symptoms in the different varieties of PME, and on clinicopathological correlations in those patients who came to autopsy (DeBarsy, et al., 1968). This report describes the clinical, electrophysiological and pathological study of two cases of PME.

\section{PATIENT AND METHODS}

Case 1. (AY) a 16 year old girl was in good health until age 9 when she developed occasional, sudden and uncontrollable jerking in her arms, especially while performing a task. Six months later her first grand mal seizure occurred. These seizures recurred every- one to two months until treatment with phenytoin and phenobarbital was started, six months after the onset of her seizures. She continued school for 3 years following the onset of her illness and finished her last 3 years of primary school with honors. She abandoned further schooling, however, because of her inability to walk without risking sudden and hazardous falls. Her first hospitalization was at age 13 , one year after leaving school. She has had only two grand mal seizures since the start of anticonvulsant therapy, but the sudden muscular jerkings have continued and have increased in frequency over the past 7 years. She is the oldest child of a non-consanginous marriage with 2 sisters and 2 brothers. No other family member is afflicted with a similar disease nor has epilepsy. Her past medical history was unremarkable. On her first admission (September, 1974) she was found to be alert, oriented and cooperative. She appeared well-nourished and physical examination did not show any abnormality. Her intellect, as estimated by routine bedside methods, was normal.

Neurological findings were limited to those in the motor system. Muscular power, bulk and tone were normal when tested at those times when there was no sudden, spontaneous movement (myoclonus). However, the assumption of a posture necessary for performing task, and the execution of such tasks, was often interrupted by frequent, sudden, unpredictable, asynchronous, and at times, violent contractions of the muscles involved. In her worst moments, she was unable to drink, comb her hair, or walk. Her gait acquired a wide-based jerky character, as though she was walking on a springboard. However, because of the presence of action myoclonus, it was always difficult to ascertain the existence of disordered cerebellar funtions. Speech was irregular and interrupted by very brief sudden halts but was not slurred. Nystagmus was absent. In the 3 years following her first admission she was treated with carbamazepin, $600 \mathrm{mg}$. qd. and primidone, $750 \mathrm{mg}$. qd. This regimen effectively controlled her grand mal seizures. Additionally she was given clonazepam, 4-6 mg. qd. in the past 2 years. The latter drug was by far the most effective medicine in controlling the myoclonic jerkings, thus enabling her to walk independently with fewer falls and to use her hands for simple tasks. It was not until then, however, that the presence of a "cerebellar" component was demonstrable in performing standard tests.

Over the past 2 years her course has been characterized by a slowly progressive dementia demonstrated by formal psychometric evaluation. There was no evidence of chronic intoxication with her anticonvulsant medications when IQ measurement was carried out. (Using the Weschler Adult Intelligence Scale, her verbal IQ was 56 while the measurement of performance IQ was precluded by the occurrence of myoclonic jerks). 
Case 2. (ZN) a 16 year old girl was born and raised in a rural region. She is the oldest child of a consanginous marriage (the parents are first cousins). She experienced her first grand mal. attack at the age of 8 which recurred every 1 to 2 months for a period of 9 months. The seizure disorder has since been treated with phenytoin and phenobarbital $(200 \mathrm{mg}$. and $90 \mathrm{mg}$. qd. respectively) with good results. Two years after the onset of these grand mal attacks she began having sudden, brusque, unpredictable muscular twitches that increased in frequency over the past 6 years. Education began at age 10 (due to regional circumstances) but was stopped after 3 months due to her inability to walk without the risk of frequent falls. She was first admitted in May, 1975. Past medical history was non-contributory. She has 4 brothers and 2 sisters, the youngest being a 2 year old boy. None of the members of her family are affected by a similar condition. A paternal uncle is said to have grand mal attacks.

General physical examination was remarkable only for the presence of a short neck which was explained by the existence of a Klippel-Feil malformation shown by cervical spine $x$-ray. Neurological findings were the same as those described in Case 1. Her intelligence in the first admission was judged normal. She received phenytoin and phenobarbital for her grand mal seizures and clonazepam (2-4 mg. qd.) for the treatment of her myoclonus. The use of clonazepam resulted in the reduction of myoclonic movements, both in their number and intensity. As in the first case, this was followed by the unmasking of an underlying cerebellar disturbance. The most remarkable change in ther condition over the past 2 years has been the gradual development of dementia in the absence of clinical or laboratory evidence of an intoxication with anticonvulsant drugs.

\section{LABORATORY FINDINGS}

The results of the following tests were normal in both patients: Complete blood count with white cell differential; erythrocyte sedimentation rate; blood urea nitrogen and serum electrolytes; CSF protein, sugar and VDRL; serum levels of ceruloplasmin and copper; skull $\mathrm{x}$-ray and computerized axial tomography.

\section{EEG AND ELECTROKYMOGRAPHY}

Recordings were made by an 8 channel machine (Schwarzer, W. Germany). The EEG in a drug free state showed frequent scattered or generalized spike and polyspike-slow wave complexes. Between the paroxysmal episodes the basic pattern consisted of alpha activity with variable amplitude and organization. A severe myoclonic jerk was almost always associated with the occurrence of a bilateral generalized polyspike complex with or without slow activity. Paroxysmal high voltage slow activity of 3-4 cycles/second was also seen. Clinical improvement as a result of anticonvulsant therapy was associated with a change of the tracing towards the normal state. Photostimulation usually, but not always, exacerbated the EEG abnormalities.

The method used for kymographic recording was based on the following observation: With the EEG machine on and the recording paper moving, free hanging electrode wires were sensitive to movements which occurred within a certain distance from them (capacity to ground transient). The fidelity of the recording system was reflected in the similarity of the shape of the recorded signals with the performance of rapid alternating movements (eg. pronation-supination) in the vicinity of the electrode wire tips. The use of this well-known
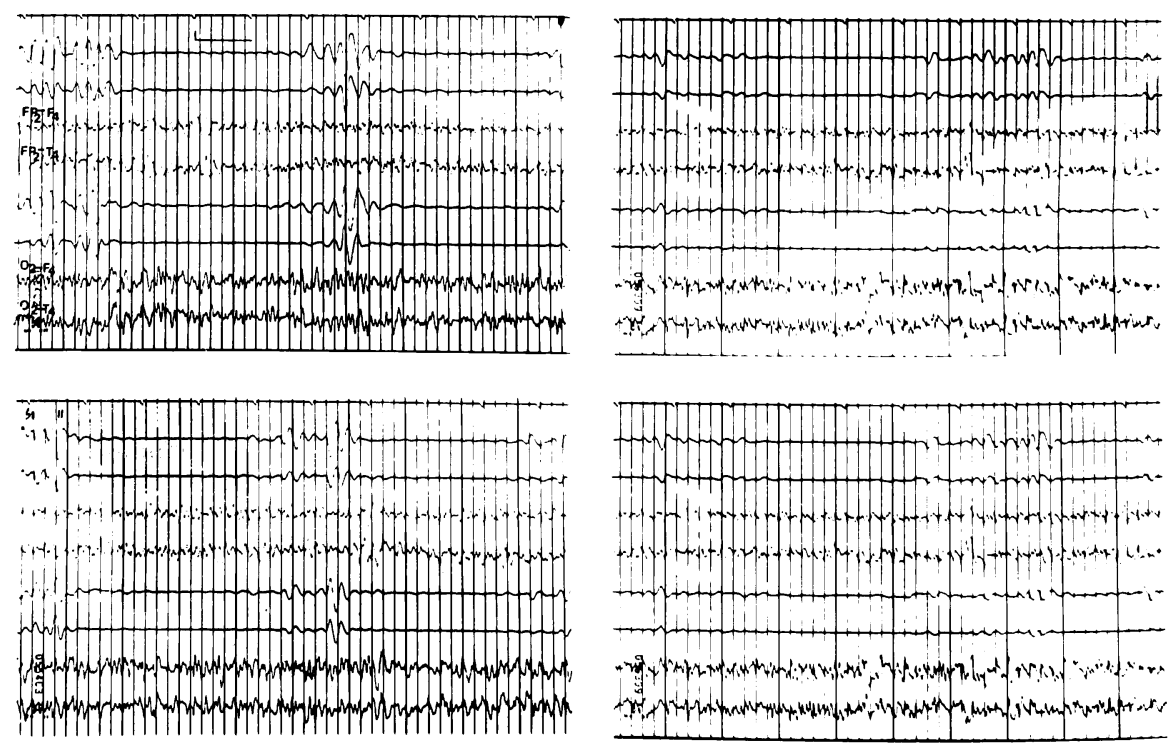

Figures 1 and 2-Represent two stretches of simultaneous EEG and electrokymography, each of 20 second duration, in Cases 1 and 2. The tremor is registered in Lines 1 and 2 , and 5 and 6 . The recording was made by an 8 channel Schwarzer EEG machine. Specifications: Single reduction switch-1, upper frequency limit-70, lower frequency limit (time constant)-0.03, attenuators-1. Ordinate- 25 microvolt. Abscissa- 0.5 second. artifact provided the means for recording the EEG from one narily used for recording the potentials from the other hemisphere) were registering the motions of the patient's approaching hand. The patient performed a standard finger-nose test, using the horizontally arranged wire tips in place of the examiner's finger. The wires were hung over a small supporting device within arm's length of the patient. When the ambient space around the wires was undisturbed the resulting record from each of the wires was a straight line. A bipolar mode of recording was used. Figures 1 and 2 show the simultaneous EEG (from left hemisphere) and electrokymography (right hand movements) recording while the patient carried out a "near wire to nose" test. The sinusoidal waves reflect the distal intention tremor of the hand while reaching to and moving away from the wire tips. hese records were made during therapy. It can be seen that the configuration of the kymographic recordings were not affected by the nature of the simultaneously occurring cortical discharges. hemisphere at the same time that the free hanging electrode wires (ordi- 
HISTOLOGICAL FINDINGS

Informed written permission was obtained from the parents of both patients for a diagnostic cerebellar biopsy. A left posterior fossa craniectomy was done under general anesthesia. The exposed cerebellum had a normal appearance in both patients. A piece of the tissue measuring $1 \mathrm{~cm}$. in all dimensions was removed from the posterior lobe, $2 \mathrm{~cm}$. away from the midline. Both patients tolerated the procedure well and were back to their pre-operative states in 3 days. Appropriate samples were preserved and processed routinely for light microscopy. Five micron sections were made for hematoxylin-eosin, Nissl, Loxol fast blue, Bodian, and periodic acid Schiff stains. Microscopic examination showed a definite loss of Purkinje cell population as compared with sections from autopsy material used for control. The majority of remaining Purkinje cells were small, misshappen and in various stages of degeneration. No hyperplasia of Bergman's glial cells nor evidence of an inflammatory response was noted. There were no inclusion bodies and no evidence of a storage disease. The

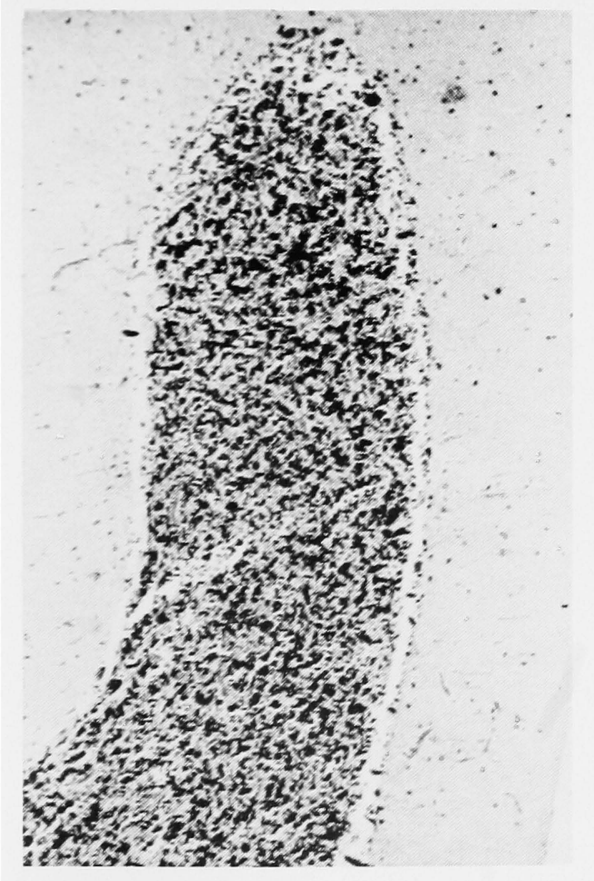

Figure 3-Cerebellar folium showing decreased Purkinje cell population. Bergmann's glia proliferation is not seen. Hematoxylin-eosin, x 100. molecular layer was slightly atrophic. No definite abnormality was noted in the cerebellar white matter (Figure 3).

\section{DISCUSSION}

Our patients' conditions were characterized by the presence of severe intention or action myoclonic jerkings and the occurrence of grand mal epilepsy. A decline in the intellectual functions of both patients was evidenced. The choice of the biopsy site was based upon the results of clinical and electrodiagnostic findings and the fact that in some cases of Lafora's disease the inclusions have been found exclusively in the brain (Scelsi, et al., 1976), particularly in the Purkinje cells. The severity of the myoclonic jerks were such that both patients abandoned their daily activities and were confined to living at home. Microscopic examination of the biopsy material did not show Lafora bodies nor evidence of neuronal storage disease of lipidotic or other types associated with the category of diseases under discussion (Harriman et al., 1955; Pallis et al., 1967; King, 1975). We thus concluded that the condition in our patients was probably of the degenerative type (Mathews et al., 1969).

The presence of symptoms of cerebellar disturbances in different diseases with myoclonic epilepsy has been noted by earlier observers (Halliday, 1967) as well as the difficulty in ascertaining the existence of such symptoms in patients with severe myoclonic jerking (Harriman et al., 1955; Noad and Lance, 1960; Hallett et al., 1977). The unmasked side to side movement observed and recorded in our patients, while under anticonvulsant therapy, had the features of what is called "cerebellar tremor". However, the problem of excluding a cortical electrical disturbance as the pathophysiological basis of the observed motor dysfunction ("cerebellar tremor"), in patients with severe action myoclonus, still remains. A confident differentiation is likely to be impossible on clinical grounds alone. The electrokymographic method described in this article is a simple and useful technique for that purpose. The accuracy of this method can be enhanced by the use of an averaging technique for the detection of cortical discharges that are sometimes missed by conventional EEG method (Shibasaki and Kuroiwa, 1975).

The relationship between myoclonic jerkings associated with cortical discharges and seizure disorder was pointed out by Grinker et al., (1938). This intimate relationship is at once evident when one witnesses the evolution from a myoclonic state into a grand mal attack while an EEG is being recorded (Derakhshan, personal observation). The electrophysiological correlates of myoclonic jerking as it relates to cortical discharges and abnormal somatosensory evoked responses has been extensively studied (Halliday, 1967; Halliday, 1975; Hallett, et al., 1977b). Recent data suggests that the mechanism of one type of myoclonus is hyperactivity of a reflex mediated in the reticular formation of the medulla oblongata (Hallett, et al., 1977a). Although the reason for this increased excitability remains speculative, the inhibitory role of the Purkinje cell discharges (Thach, 1968; Eccles, 1969) and the existence of a cerebelloreticular connection (Warwick and Williams, 1973) can provide a possible explanation for this finding in those cases with loss of Purkinje cells.

We found striking similarities between the clinical findings in our patients and some of the cases (Cases 1-4) described by Ramsay Hunt (Hunt, 1921). Being aware of the nosological controversy on this subject (DeBarsy et al., 1968; Radermecker, 1977; Roger et al., 1968), we believe that the clinical aspect of this confusion is due to the difficulty of ascertaining the existence of a distinct cerebellar disturbance in patients with different varieties of PME. Simultaneous EEG and electrokymographic recording is a useful method to differentiate action (intention) myoclonus from intention tremor; the latter considered to be cerebellar in its genesis.

\section{REFERENCES}

DeBARSY, T., MYLE, G., TROCH, D., MATHYS, R., and MARTIN, J. (1968). La dyssynergie cerebelleuse myoclonic ( $R$. Hunt). J. Neurol. Sci., 8, 111-127. 
ECCLES, J. C. (1969). The inhibitory pathways of the central nervous system. Illinois: Charles C. Thomas. pp. 74-100.

GRINKER, R. R., SEROTA, H., and STEIN, S. I. (1938). Myoclonic epilepsy. Arch. Neurol. Psychiat., 40, 968-980.

HALLETT, M., CHADWICK, D., ADAM, J., and MARSDEN, C. D. (1977a). Reticular reflex myoclonus: a physiological type of post-hypoxic myoclonus. J. Neurol. Neurosurg. Psychiat., 40, 253-264.

HALLETT, M., CHADWICK, D., and MARSDEN, C. D. (1977b). Ballistic movement overflow myoclonus: a form of essential myoclonus. Brain, 100, 299-312.

HALLIDAY, A. M. (1967). The clinical incidence of myoclonus. In: Modern Trends of Neurology, Vol. 4. Edited by D. Williams. London: Butterworths. pp. 69-105.

HALliDAY, A. M. (1975). The neurophysiology of myoclonic jerking a reappraisal. In: Myoclonic Seizures. Edited by M. $\mathrm{H}$. Charlton. Amsterdam: Excerpta Medica International Congress Series. No. 307, pp. $1-29$.
HARRIMAN, D. G. F., MILlAR, J. H. D., and STEVENSON, A. C. (1955). Progressive familial myoclonic epilepsy in three families: its clinical features and pathological basis. Brain, 78, 325-349.

HUNT, J. R. (1921). Dyssynergia cerebellaris myoclonica-primary atrophy of the dentate system: a contribution to the pathology and symptomatology of the cerebellum. Brain, 44, 490-538.

KING, J. O. (1975). Progressive myoclonic epilepsy due to Gaucher's disease in an adult. J. Neurol. Neurosurg. Psychiat., 38, 849854.

MATHEWS, W. B., HOWELL, D. A., and STEVENS, D. L. (1969). Progressive myoclonus epilepsy without Lafora bodies. J. Neurol. Neurosurg. Psychiat., 32, 116122.

NOAD, K. B., and LANCE, J. W. (1960). Familial myoclonic epilepsy and its association with cerebellar disturbance. Brain, 83, 618-630.

PALLIS, C. A., DUCKETT, S., and PEARSE, A. F. E. (1967). Diffuse lipofuscinosis of the central nervous system. Neurology, 17, 381394.
RADERMECKER, F. J. (1977). Degenerative disorder. In: Handbook of Electroencephalography and Clinical Neurophysiology. Edited by A. Remond. Amsterdam: Elsevier. pp. 169-175.

ROGER, J., SOULAYROL, R., and HASSOUN, J. (1968). La dyssynergie cerebelleuse myoclonique (syndrome de Ramsay Hunt). Rev. Neurol., 119, 85-106.

SCELSI, R., MAZELLA, G. L., and LOMBARDI, M. (1976). Myoclonus epilepsy with cerebellar Lafora bodies. J. Neurol. Neurosurg. Psychiat., 39, 357-381.

SHIBASAKI, J., and KUROIWA, Y. (1975). Electroencephalographic correlates of myoclonus. Electroencephalography and Clinical Neurophsiology, 39, 455-463.

THACH, W. T. (1968). Discharge of Purkinje and cerebellar nuclear neurons during rapidly alternating arm movements in the monkey. J. Neurophysiol., 31, 785-797.

WAR WICK, P., and WILLIAMS, P. L. (1973). Gray's Anatomy. W. B. Saunders, 35th British edition. pp. 859-864. 